\title{
O lugar dos Conselhos Municipais de Educação nos PMEs relativos ao PNE 2001-2010
}

Donaldo Bello de Souza Universidade do Estado do Rio de Janeiro

Alzira Batalha Alcântara Universidade do Estado do Rio de Janeiro

Universidade Estácio de Sá

\section{Resumo}

Este artigo, com base em análise documental, investiga o papel dos Conselhos Municipais de Educação (CME) na discussão, elaboração acompanhamento e avaliação em 10 Planos Municipais de Educação (PMEs) da Região Metropolitana do Rio de Janeiro, relativos ao Plano Nacional de Educação (PNE) 200 1-2010. Observou-se que, embora os dez municípios tenham destacado a participação da sociedade civil na construção dos planos, os Conselhos, em geral, não tiveram um lugar de destaque na gestão democrática da educação local. Identificou-se, também, uma baixa cooperação intermunicipal, nos termos da previsão de realização de ações de gestão conjunta dessas cidades para o enfrentamento dos desafios educacionais locais.

Palavras-chave: Conselho Municipal de Educação. Plano Municipal de Educação. Gestão democrática e cooperação intermunicipal.

\section{The place of the Municipal Councils of Education in PMEs related to PNE 2001-2010}

\section{Abstract}

This article, based on document analysis, investigates the role of the Municipal Councils of Education in the discussion, development, monitoring and assessing of 10 Municipal Education Plans (PMEs) from the metropolitan region of Rio de Janeiro, related to the National Education Plan (PNE) 2001-2010. We have noticed that, although the ten municipalities have featured the participation of civil society in the constructions plans, the Councils, generally, did not have a place of prominence in the democratic management of local education. We have identified, also, a low inter-municipal cooperation, in accordance with the estimates of carrying out actions of joint management of these cities to face the local educational challenges.

Keywords: Municipal Council of Education. Municipal Education Plan. Democratic management and intermunicipal cooperation. 


\section{El lugar de los Consejos Municipales de Educación en los PMEs rela- cionados com el PNE 2001-2010}

\section{Resumen}

Este artículo, basado en el análisis de documentos, investiga el papel de los Consejos Municipales de Educación en La discusión, desarrollo, seguimiento y evaluación en 10 Planes Municipales de Educación (PMEs) de la región metropolitana de Rio de Janeiro, relacionados con el Plan Nacional de Educación (PNE) 2001-2010. Se observó que aun que los diez municipios destacaron La participación de la sociedad civil en los planes de construcción, los Consejos, generalmente, no tenían un lugar prominente en la gestión democrática de la educación local. Se identificó también una cooperación intermunicipal baja, según la previsión de la realización de acciones conjuntas de manejo en estas ciudades para hacer frente a los retos educativos locales. Palabras clave: Consejo Municipal de Educación. Plan Municipal de Educación. Gestión democrática y La cooperación intermunicipal.

\section{Introdução}

A Constituição Federal de 1988 (BRASIL, 1988), ao recuperar as bases federalistas do Brasil, redistribuiu a autoridade política entre os entes federados, incluindo também, a partir deste momento, os municípios como atores polííicos autônomos. Isto veio a significar, entre outras dimensões, a possibilidade de os estados, Distrito Federal e agora os municípios, ao lado da União, formularem e implementarem suas próprias políticas.

Assim, elevados à condição de entes federados, veio a ser facultado aos municípios o exercício da autonomia, especialmente em termos da criação dos seus sistemas de ensino. Tal previsão constitucional foi regulamentada pela Lei de Diretrizes e Bases da Educação Nacional n 9.394, de 20 de dezembro de 1996 (BRASIL, 1996), que discriminou as incumbências legais educacionais dos entes federados. Assim, de acordo com a LDB, cabe ao município, entre outras incumbências, "[...] organizar, manter e desenvolver os órgãos e instituições oficiais dos seus sistemas de ensino, integrando-os às políticas e planos educacionais da União e dos Estados" ou, no caso de não optarem pela constituição dos seus próprios sistemas, integrarem-se "[...] ao 
sistema estadual de ensino ou compor com ele um sistema único de educação básica" (BRASIL, 1996).

Na segunda metade da década de 1990, a ideia de formulação de um plano de educação - coerentemente ao previsto na Constituição Federal de 1988 (BRASIL, 1988) e na LDB n²9.394, de 20 de dezembro de 1996 (BRASIL, 1996) - veio a afetar os municípios brasileiros de uma dupla forma: de um lado, no momento em que o Plano Nacional de Educação (PNE) 2001 2010 foi elaborado - Lei n 10.172, de 9 de janeiro de 2001, que "Aprova - Plano Nacional de Educação - PNE e dá outras providências" (BRASIL, 20011 -, pois pressupôs a participação do conjunto da sociedade brasileira, incluindo-se, portanto, os espaços locais, e, de outro, quando essas mesmas localidades vieram, assim como os estados, ser chamadas à tradução desse plano para a realidade municipal, dando corpo aos Planos Municipais de Educação (PMEs) (BRASIL, 2001).

Todavia, chegado ao término da vigência do PNE 2001-2010 (BRASIL, 2001), contabilizou-se a existência, em 2014, de 14 estados sem Plano Estadual de Educação (PEE) (54\% do total de 26), além do Distrito Federal, (SOUZA; MENEZES, 2014), e, em 2011 , de cerca de 2.181 municípios (39,2\% de 5.565) sem Plano Municipal de Educação (PME) (BRASIL, 2012). Somou-se a esses déficits a ausência de um novo PNE que, originalmente, conforme previsto no PL n 8.035, de 20 de dezembro de 2010 (BRASIL, 201 1), de autoria do Poder Executivo federal, deveria vigorar no decênio 201 1-2020, mas cujo trâmite legislativo consumiu deste período cerca de três anos e meio, tendo sido aprovado somente em 25 de junho de 2014, por meio da Lei n 13.005, de 25 de junho de 2014, que "Aprova o Plano Nacional de Educação - PNE e dá outras providências" (BRASIL, 2014) -, agora, abarcando o decênio 2014-2024.

Sobre os PMEs aprovados no país, resultantes dos desdobramentos do PNE 2001-2010 - que, em tese, deveriam apresentar articulações com o planejamento local da educação -, é possível afirmar, conforme levantamento minucioso realizado por Souza \& Sousa (2012), que pouco se sabe a seu respeito, isto em função da escassez dos estudos que os tomam por alvo. Segundo Souza \& Duarte (2014), até o último ano de vigência do PNE 2001 2010 , apenas seis $(22,2 \%)$ das 27 unidades federadas expunham exame científico de, pelo menos, um dos seus PMEs, a saber: Rio Grande do Sul (WERLE; BARCELLOS, 2008), Paraná (SANTOS, 2004), Rio de Janeiro (VILLELA, 
2008), Mato Grosso do Sul (BARBOZA, 2008), Alagoas (OlIVEIRA; ARAGÃO, 2010 ) e Rio Grande do Norte (SOUZA, 2006). Essas pesquisas se ocupam do exame do caráter mais ou menos democrático relativo ao processo de construção do plano, visando à análise do nível e grau da participação sociopolítica local, dedicando pouca ou nenhuma atenção ao conteúdo desse instrumento (SOUZA; DUARTE, 2014).

Igualmente escassas são as informações sobre a atuação dos Conselhos Municipais de Educação (CMEs) na discussão e elaboração dos PMEs no país, assim como em relação à previsão do seu papel na promoção das etapas e modalidades da Educação Básica e, sobretudo, em termos do acompanhamento e avaliação do plano propriamente dito. A importância dessas questões vai ao encontro do entendimento de que esses órgãos colegiados constituem-se em espaços que, de um lado, podem vir a favorecer o controle social local das políticas públicas de educação (SOUZA; VASCONCELOS, 2008), já que potencialmente se voltam para a participação da sociedade civil na sua gestão (GOHN, 200 1), mas que, de outro, em função da manifestação de uma cultura política clientelista, fisiologista e corporativa, podem implicar desmobilização social e deterioração do próprio exercício da cidada194 nia (NOGUEIRA, 1997).

Assim, este artigo visa ao exame do papel desempenhado pelos CMEs na discussão e elaboração de PMEs, na promoção das etapas e modalidades da Educação Básica e, ainda, no acompanhamento e avaliação do plano propriamente dito. Para tanto, toma por base empírica os planos pertencentes a 10 municípios da Região Metropolitana (RM) do Rio de Janeiro, aprovados pelas Câmaras Municipais no período 2001-2012, conexos ao PNE 2001 2010, mais adiante discriminados.

Consiste em um estudo de caráter exploratório (KETELE; ROEGIERS, 1993), metodologicamente ancorado na análise de conteúdo (BARDIN, 2004), em particular de documentos legislativos (RODRIGUES, 201 1), configurando um dos produtos de pesquisa de maior amplitude analítica, que, além de enfocar os processos já mencionados de forma mais ampla, analisa, também, as vinculações desses planos com outros instrumentos de gestão local da educaçãol.

Além desta seção, o texto possui outras cinco partes. Na próxima, apresenta-se um panorama acerca dos CMEs e PMEs no Estado do Rio de 
Janeiro expondo, de um lado, os principais problemas que vêm marcando o funcionamento institucional e político desse órgão colegiado, e, de outro, a situação desses planos no estado, em particular no que remete à caracterização daqueles que serão tomados por alvo das análises. As três seções seguintes versam sobre a análise desses PMEs visando, em respectivo, ao papel dos CMEs: na discussão e elaboração desses planos, na promoção das etapas e modalidades da Educação Básica e, ainda, no seu acompanhamento e avaliação. Por último, intenta-se traçar um perfil geral acerca do lugar que esses Conselhos ocupam nos planos examinados.

\section{CMEs e PMEs no Estado do Rio de Janeiro}

De acordo com a Pesquisa Munic do Instituto Brasileiro de Geografia e Estatística (IBGE), relativa ao ano de 2011 , a quase totalidade dos municípios do Estado do Rio de Janeiro informou ter constituído os seus respectivos sistemas de ensino - 80 (87\%) do total de 92 localidades -, sendo que apenas 12 (13\%) o possuíam vinculado (e não integrado) ao Sistema Estadual de Ensino (BRASIL, 2012 ). Ainda com base neste total, 100\% declararam possuir $C M E$, expondo elevado equilíbrio entre o exercício das competências e funções clássicas: 75 (81\%) a consultiva, 81 (88\%) a deliberativa, 75 (81\%) a normativa e $74(80 \%)$ a fiscalizadora.

Sobre a criação e o funcionamento institucional e sociopolítico dos CMEs fluminenses, muitos são os problemas apontados por algumas pesquisas. Por exemplo, na investigação levada a efeito por Souza e Vasconcelos (2012, p. 53), que considerou 28 de suas localidades, foi constatada, entre outros aspectos, a pouca preocupação dos Sistemas Municipais de Ensino em relação ao que denominaram "competência técnica" do conselheiro, o que tornaria ainda mais complexa a operacionalização dos CMEs, dificultando a efetivação de um processo participativo "[...] mais consciente por parte daqueles que representam setores da sociedade civil, alguns leigos em termos da administração pública e da legislação educacional [...]" (SOUZA; VASCONCELOS, 2012 , p. 531.

Outra contribuição para o conhecimento dos problemas que marcam esses conselhos no estado do Rio de Janeiro decorre da revisão da literatura científica e acadêmica relacionada aos estudos teórico-empíricos sobre os 
CMEs fluminenses, realizada por Souza \& Vasconcelos (2013), que confirmam as tendências já identificadas.

Em relação aos PMEs fluminenses, cabe destacar que, em 2008, apesar de o estado do Rio de Janeiro ainda não possuir o seu Plano Estadual de Educação (PEE)², a Assembleia Legislativa do Estado do Rio de Janeiro (Aleri) buscou conduzir os municípios fluminenses à elaboração dos seus PMEs. Para isto, promulgou a Lei n ${ }^{\circ}$ 5.332, de 24 de novembro de 2008 - que dispõe sobre as transferências de receita aos municípios que constituírem o Plano Municipal de Educação -, prevendo a suspensão de transferências de receitas próprias do estado, "respeitando os limites constitucionais legais" (RIO DE JANEIRO, 2008), para localidades que até 2010 não elaborassem o seu plano, aprovado pela Câmara Municipal.

Em 2012 , após amplo levantamento documental ${ }^{3}$, os autores do presente texto lograram localizar33 PMEs e suas respectivas leis, na sua quase totalidade aprovados ao longo da vigência do PNE 2001-2010, correlatos a 36\% dos 92 municípios do estado, neste caso, 15 planos a menos do total cujas leis constavam indicadas, em 2011 , nos registros da Alerj (cf. VASCONCELOS, PEIXOTO, VIDAL, 2012), e 38 a menos do total declarado 196 para a Munic/IBGE (BRASIL, 2012).

Daquele universo de 33 PMEs localizados por esses autores ${ }^{4}$, verificou-se que somente 10 pertenciam a municípios da RM do Rio de Janeiro ${ }^{5}$, expressão de 53\% do total de 19 localidades que compõem a referida região. Se apenas 10 (53\%) dos 19 municípios que integram a RM do Estado do Rio de Janeiro possuem PMEs (até dezembro/2012), também é possível afirmar que o movimento para a elaboração de seus respectivos planos não ocorreu de forma imediata à aprovação do PNE 2001-2010 (BRASIL, 2001). Afinal, desses 10 planos, somente Nilópolis (200 l a) elaborou e aprovou o plano em 2001, ou seja, no mesmo ano em que aquele plano nacional veio a ser regulamentado por lei. Com exceção de Nilópolis (200 la), os demais municípios aprovaram seus respectivos planos a partir do $6^{\circ}$ ano de vigência do PNE em questão: São Gonçalo (2006) em 2006; Itaboraí (2008), Japeri (2008), Maricá (2008), Niterói (2008) e Rio de Janeiro (2008) em 2008; Queimados (2009) e Tanguá (2009) em 2009 e Seropédica (2012) justamente quando a validade do PNE já expirara, em 2012. 


\section{CMEs na discussão e elaboração dos PMEs}

A Constituição Federal de 1988 (BRASIL, 1988) proporcionou uma nova engenharia institucional na área da educação, possibilitando ao município, entre outras questões, organizar um sistema de ensino em sua esfera governamental, prescrevendo a gestão democrática no ensino público e, a um só tempo, estimulando o surgimento de Conselhos como mecanismo institucionalizado de participação sociopolítica.

Esse novo cenário constituiu, também, resultado da influência de diversos movimentos democrático-populares, iniciados ao longo das décadas de 1960 e 1970, manifestos em várias frentes de lutas sociais (GOHN, 2008; CALDERÓN, 2008; CALDERÓN; MARIM, 2002). Decorre, igualmente, de experiências remanescentes de alguns outros movimentos sociais dos idos de 1980 (GOHN, 2001 ) que, no seu conjunto, lograram êxito em estabelecer pressões em prol de ideais democráticos e de institucionalização de novas redes associativas e canais de participação popular na esfera da gestão pública (DUARTE; SANTOS, 2014; LUCHMANN, 2007). Neste contexto, a educação destacou-se como uma das áreas, ao lado de outras como saúde, que possibilitou maior abertura para as contribuições da sociedade civil organizada.

Entretanto, há desafios de distintas ordens para a efetivação de uma gestão participativa, como a persistência de uma cultura patrimonialista que trata a coisa pública como algo privado, além de uma política elitista que naturaliza o protagonismo de poucos. Nossas raízes escravocratas, as acentuadas desigualdades sociais e econômicas ainda presentes ajudam a entender como essas práticas vêm rasgando o tempo. Há mecanismos políticos que, historicamente, aniquilam a organização dos setores populares, ou inibem a participação desses grupos (CARVALHO, 2002). Tais práticas reiteram uma cidadania restritiva, em que a maioria não se percebe como portador de direitos e não crê no Estado como meio para avançar na resolução de seus problemas, pondo em xeque a própria democracia (POMPEU, 2008).

Ainda assim, é possível afirmar que os CMEs podem desempenhar um papel de fundamental importância na gestão pública local, cabendo a ele, grosso modo, regular o sistema de ensino municipal. Entretanto, não se trata de um órgão regulador qualquer, pois nele devem estar representados o governo e a sociedade civil organizada, sendo, portanto, um mecanismo que pode dar voz e vez à comunidade. Todavia, há desafios distintos. Bordenave (2011) 
aponta que existem diferentes acepções e graus de participação e esta não pode ser igualitária nem democrática quando a estrutura de poder concentra as decisões numa elite minoritária.

Os PMEs constituem-se em exemplos típicos da importância do CME na construção das políticas públicas municipais na área da educação. Conforme sinalizado por Monlevade (2004, p. 40), "O papel de dar o comando, de coordenar a elaboração, de executar as ações necessárias" à construção local do PME e posterior execução e avaliação consiste, de fato, à SME, mas no caso de haver um CME "[...] com poder normativo ou somente consultivo, é dele o papel primordial de inspirar, incentivar, cobrar e orientar todo o processo de elaboração, execução e avaliação [...]" do plano. Nesta perspectiva, caberia aos CMEs suscitar as discussões sobre o plano, de modo a estimular a participação da comunidade na elaboração de propostas, cooperando, portanto, com a SME, sem sobrepor-se a este órgão (BRASIL, 2007).

No que tange ao processo de discussão e elaboração dos PMES da RM do Rio de Janeiro sob análise, constata-se que os 10 municípios destacaram, em maior ou menor grau, a importância da participação da sociedade civil na sua elaboração, ainda que alguns não tenham explicitado quais os 198 principais atores sociais envolvidos e sequer a forma como ocorreu esse processo, atendo-se a uma descrição genérica que não colabora na tarefa de qualificação desse processo. Entretanto, cabe realçar que o CME, espaço privilegiado para uma construção democrática da gestão educacional, foi citado em todos os planos, mas apenas em 5 (cinco) - Japeri, Niterói, Rio de Janeiro, São Gonçalo e Seropédica - teve um papel de destaque, visto que participou da elaboração, análise e sistematização do documento final e/ou da coordenação do processo como um todo.

Em Japeri (2008a), o início do processo de construção do plano coube ao CME, por meio do qual se instituiu uma comissão que construiu os referenciais teóricos do plano. Realizou-se um fórum com a participação de gestores e equipe técnica com o intuito de mapear a realidade educacional japeriense e organizar fóruns que ocorreram em todas as unidades escolares. Este movimento revelou a necessidade de aprofundar o diagnóstico da educação local e, para tanto, a Secretaria Municipal de Educação e Cultura (SEMEC) organizou um minicenso educacional, envolvendo o conjunto das escolas e a comunidade em geral. A Comissão analisou os dados, tendo também sistematizado a primeira versão do plano que foi encaminhado às escolas 
com o objetivo de avaliarem e tecerem novas sugestões, as quais foram sistematizadas pela Comissão. A discussão e a elaboração do PME envolveram as unidades escolares e a comunidade em geral, tendo o CME e a SEMEC como protagonistas desse processo (JAPERI, 2008a).

Em Niterói, o PME foi construído entre 2003 a 2007. No mesmo ano em que se iniciou o PME, foi constituído um "Comitê Executivo, com representantes da SME, da Fundação Municipal de Educação (FME) e do CME, para definir os fundamentos desse processo" (NITERÓl, 2010, p. 3). Com isto, instalou-se o Fórum Municipal de Educação, que realizou diversos encontros, contando com a participação de entidades da sociedade civil que atuam, direta ou indiretamente, com a educação na cidade, a fim de debater as metas, ações e os prazos que integrariam o plano. A partir de 2005, o CME assumiu a coordenação do PME, cuja aprovação veio a ocorrer na $1^{a}$ Conferência Municipal de Educação de Niterói, em 2007, e transformado em lei no ano seguinte (NITERÓl, 2010).

No Rio de Janeiro, o plano foi elaborado entre os anos de 2003 e 2004, mas só foi aprovado e publicado em 2008. $\bigcirc$ trabalho de construção do plano foi coordenado pelo CME, tendo como ponto de partida a realização de um seminário na Câmara dos Vereadores. Buscou-se dialogar com autoridades educacionais dos mais variados níveis e, igualmente, envolver a rede por meio de "Conselhos eleitos dos diversos segmentos, que compõem a comunidade escolar e as demandas contidas no Plano Estratégico da Cidade do Rio de Janeiro" (RIO DE JANEIRO, 2008b, p. 1).

Em São Gonçalo, o plano foi elaborado entre 2003 a 2004, mas só foi aprovado pelo legislativo em 2006. A SME organizou oito fóruns temáticos, com a participação da comunidade, para elencar as metas do plano. Estas vieram a ser analisadas pelas equipes técnicas da Secretaria, "[...] ajustadas às teorias e legislação vigentes, colocadas dentro das disponibilidades orçamentárias e reapresentadas à consideração da comunidade para apreciação final" (SÃO GONÇALO, 2006a, p. 1). A partir desse movimento, a Secretaria construiu a versão final do documento que foi encaminhado ao CME. Os conselheiros analisaram o documento e emitiram um parecer favorável. Se a SME foi protagonista no processo de elaboração do plano, o CME teve destaque na análise do mesmo. 
Em Seropédica, o plano foi construído ao longo de 2011 e aprovado no legislativo no ano seguinte, sendo, portanto, o único plano aprovado, no rol dos municípios analisados, após a vigência do PNE 2001-2010 (BRASIL, 20011 . A elaboração do plano iniciou-se com um amplo debate nas escolas da rede pública municipal e contou com a "participação da comunidade, professores, equipe pedagógica, funcionários, pais e alunos" (SEROPÉDICA, 2011 , p. 9). Tais debates propiciaram a elaboração de um documento referência que foi o esteio das duas Conferências Municipais de Educação. Com o intuito de assegurar um processo participativo, organizou-se uma Comissão Sistematizadora composta por representantes da SME, do CME, da Universidade Federal Rural do Rio de Janeiro (UFRRJ), do Sindicato dos Profissionais da Educação (SEPE), da Associação Nacional pela Formação de Profissionais da Educação (ANFOPE) e da Câmara de Vereadores. Essa Comissão não só coordenou todo o processo, como finalizou a redação do documento. Ou seja, o CME de Seropédica, enquanto membro da Comissão Sistematizadora, teve importância no processo de coordenação e elaboração do PME.

Nos demais planos analisados, o CME não teve preponderância. Em 200 alguns, há informações vagas que não auxiliam na tarefa de precisar o grau de envolvimento do CME nesse processo. Maricá (2008) ilustra tal situação, pois, embora conste que o PME tenha sido elaborado pelo CME, as informações existentes são genéricas, não havendo maiores detalhes que ajudem a qualificar a natureza dos encontros, tampouco a identificação dos seus participantes. Em Itaboraí (2008a), o CME se fez representar por delegados na Conferência Municipal, porém coube à Secretaria Municipal de Educação e Cultura (Semec) o protagonismo no processo de discussão e elaboração. Neste caso, o CME veio a ganhar relevância apenas na implementação e avaliação do plano. Nilópolis (200 1) não faz referências ao CME ou a quaisquer outros conselhos, tendo explicitado a ação direta da Secretaria Municipal de Educação (Semed) no processo de construção do plano. Em Queimados (2009a), o documento do plano teria sido elaborado de forma plural, mas não constam referências à atuação do CME, ainda que a revisora técnica, profa. Dinair Hora, em seu texto que antecede o documento do plano propriamente dito, tenha valorizado esse Conselho como mecanismo chave para a construção da gestão democrática no município. Afirma que um Sistema Municipal de Educação é complexo e sua concepção incide sobre a estrutura da Semed e 
sugere que se valorizem as estruturas que são permanentes, como as escolas e - CME, sobretudo por conta das sucessões nos gabinetes dessas Secretarias. Tanguá (2009a) não faz referência ao CME como parceiro no processo de discussão e elaboração do plano. Consta apenas, de forma genérica, que houve a participação da sociedade, tendo o CME sido citado, de forma explícita, somente em algumas metas e no trabalho de acompanhamento da execução do plano.

Conforme visto, as referências ao CME como lócus de discussão e elaboração dos PMEs são relativamente escassas, embora os planos em tela se esforcem em salientar o protagonismo da sociedade civil nesse processo, mas sem precisar os espaços nos e pelos quais tal participação se daria.

\section{CMEs na promoção da Educação Básica prevista nos PMEs}

A estrutura de um PME, de forma geral, contempla introdução, caracterização do município, diagnósticos, diretrizes, objetivos, metas e ações concernentes a distintos eixos, além de uma parte dedicada ao acompanhamento e avaliação do plano. Cada PME atribui aos níveis, às modalidades de ensino, à formação e à valorização do magistério, como também ao financiamento e à gestão, metas que devem ser alcançadas por meio de ações num dado prazo. A extensão dos PMEs ora analisados é diferenciada, o que, em parte, se deve ao detalhamento de informações ou a um debate mais prolongado de certos temas em alguns planos, enquanto os mais sintéticos expõem um tom mais lacônico.

A introdução desses PMEs revela, de certa forma, o perfil do próprio plano. Alguns, como Japeri (2008a) e Queimados (2009a) tecem um debate com um viés mais político, situando o plano no contexto maior da organização educacional. Reconhecem a vitalidade de um PME na construção de uma política de Estado, mas também para a gestão democrática. Em outros, todavia, como Maricá (2008) e Tanguá (2009a), nota-se um caráter mais formal, no qual tais debates estão ausentes.

Considerando que um diagnóstico é um elemento-chave no planejamento, importa realçar que nos planos em tela nem sempre ocupam lugar de destaque. Em alguns, o diagnóstico possui caráter vago, pois prioriza considerações de âmbito nacional, princípios expressos na LDB ou problemas clássicos 
da educação do País, apoiando-se, sobretudo, em dados mais genéricos, como, por exemplo, os PMEs de Maricá (2008), Rio de Janeiro (2008), São Gonçalo (2006b) e Tanguá (2009a). Outros planos não apresentam diagnóstico propriamente dito, embora contextualizem a educação local, como ocorreu no PME de Seropédica (2011).

Entretanto, alguns municípios tiveram um maior empenho em mapear dados educacionais, não se atendo a informações vagas ou genéricas. Queimados (2009a) e Japeri (2008a) ilustram tal movimento. Queimados (2009a), embora tenha tomado o PNE como referencial, optou por agrupar alguns temas em um mesmo eixo, como a Educação Profissional e Superior, possivelmente com o intuito de respeitar as características do município que possui apenas uma instituição de nível superior e poucos cursos profissionalizantes. Cumpre também destacar que foram incorporadas a este PME, todas as propostas aprovadas na Plenária da Conferência Municipal de Educação, inclusive objetivos que extrapolam as atribuições do Sistema Municipal de Ensino, o que denota uma atitude respeitosa frente às decisões coletivas e uma coerência com o princípio da gestão democrática. Com o objetivo de conhecer a realidade local, Japeri (2008a, p. 29) realizou um minicenso educacional 202 envolvendo as escolas e a comunidade, de modo a identificar a situação educacional "[...] da população residente no município; construir subsídios para a formulação e avaliação de políticas públicas educacionais; compreender a dinâmica educacional praticada e a educação oferecida".

Do ponto de vista da previsão da atuação dos CMEs na promoção das etapas e modalidades da Educação Básica, constantes dos PMEs em questão, é possivvel afirmar que na esfera da Educação Infantil o CME consta de forma mais expressiva, seja para assessorar o processo de regularização e autorização de funcionamento da rede privada, seja para fiscalizar a infraestrutura das escolas ou para acompanhar quaisquer atendimentos concernentes ao processo pedagógico dessa faixa etária, como é possível observar nos planos de Itaboraí (2008a), Japeri (2008a), Niterói (2010), Queimados (2009a) e Rio de Janeiro (2008a). Em Niterói, destaca-se a ação voltada para mobilizar diferentes sujeitos envolvidos na Educação Infantil, de instituições públicas e privadas, conselhos municipais e sociedade civil, isto com o intuito de melhorar o atendimento à infância e contribuir para a ampliação do debate. Nota-se, ainda, a presença de uma importante meta, prevista para ser regulamentada pelo CME, de vir a "[...] garantir em todas as Unidades de 
Educação Infantil, do Sistema Municipal de Educação, o horário de planejamento e estudo semanal incluído na carga horária contratada pelo professor" (NITERÓl, 2010, p. 5). No Rio de Janeiro, cabe ao CME definir a "[...] habilitação dos profissionais que compõem a equipe pedagógica nas instituições privadas de Educação Infantil" (RIO DE JANEIRO, 2008a, p. 29 e 31 1), como também estabelecer diretrizes para o campo da formação inicial e continuada "dos gestores, professores e dos demais profissionais da Educação Infantil, principalmente daqueles que atuam na modalidade creche".

No Ensino Fundamental, o PME de Japeri (2008a, p. 57) evoca o CME e o Conselho Escolar (CE) para garantir o cumprimento dos padrões mínimos atinentes à infraestrutura das escolas, "[...] compatíveis com o tamanho dos estabelecimentos e com as realidades", incluindo diferentes aspectos, tais como: segurança, rede elétrica, iluminação, instalações sanitárias e higiene, biblioteca, mobiliário, material pedagógico. Para tanto, "antes da homologação, as plantas das construções, reformas ou ampliações dos espaços escolares" devem ser encaminhadas ao CME, CE e técnicos afins. Já o PME de Niterói prevê o estabelecimento de "[...] parcerias entre a Fundação Municipal de Educação, o Conselho Tutelar e o Conselho Municipal de Educação a fim de que sejam feitas discussões para a reformulação dos regimentos escolares, observando-se o disposto na legislação em vigor, especialmente o ECA" (NITERÓl, 2010, p. 8). No plano do Rio de Janeiro, o CME normatiza, por meio de Parecer, a universalização do Ensino Fundamental de nove anos, garantindo o acesso de crianças neste nível de ensino, a partir da idade de seis anos (RIO DE JANEIRO, 2008a).

Na esfera da Educação Especial, o CME é mencionado, de forma explícita, para incentivar a "criação do Conselho Municipal da Pessoa Portadora de Deficiência" (ITABORAí, 2008a, p.87) ou, ainda, para prescrever normas de atendimento educacional especializado (RIO DE JANEIRO, 2008a).

Já no campo do financiamento e gestão da educação, o CME é evocado para diferentes frentes, a começar pela participação no Conselho do Fundo de Manutenção e Desenvolvimento da Educação Básica e de Valorização dos Profissionais da Educação (Fundeb) e, ainda, na convocação, juntamente com a SME, de um Fórum Municipal de Educação com o intuito de promover um "[...] espaço de participação e discussão das políticas públicas para a educação no Município, a ser realizado, no mínimo, uma vez no período correspondente a cada gestão de administração municipal" 
(ITABORAí, 2008a, p. 122). Para Japeri (2008a), o CME deve, juntamente com outros conselhos, fiscalizar a aplicação dos recursos financeiros e coordenar, de forma contínua, a implantação do plano, enquanto Maricá (2008) destaca - CME apenas como responsável pelo controle social dos recursos, juntamente com o Conselho do Fundeb. Nos demais objetivos e metas, Maricá prioriza a ação dos CEs, enquanto que Nilópolis (2001) destaca o papel do CME e dos CEs na gestão e controle dos recursos financeiros. Se Niterói (2010) também valoriza a ação do CME na gestão e no controle social dos recursos, destacam-se metas que visam fortalecer o trabalho de diferentes conselhos, inclusive do próprio CME, como também garantir a formação continuada dos seus Conselheiros. São Gonçalo (2006b) e Seropédica (2011), em suas metas, também estimulam e apoiam tecnicamente o desenvolvimento do CME. Além do apoio técnico, Seropédica (201 1, p. 31 ) prevê o "[...] cumprimento das ações do Conselho Municipal de Educação, garantindo dotação orçamentária, infraestrutura e formação dos conselheiros, de acordo com a Lei Municipal n 18, de 17 de abril de 1997, a partir de 2013". Tanguá (2009a, p. 94) incentiva a população a participar de conselhos para o controle social de recursos, também valorizando a meta de ampliação da oferta de cursos de 204 formação técnica. Para tanto, cabe ao CME, como também a outros conselhos, promover uma "[...] grande mobilização popular capaz de assegurar que o Governo Estadual ofereça cursos técnicos e profissionalizantes em Nível Médio para a população tanguaense".

O CME não é um interlocutor privilegiado no plano de Queimados (2009a, p. 182). Esse município aponta que a educação, ao contrário da saúde, "[...] fragilizou seus mecanismos de participação e fiscalização dividindo-os em três conselhos: o do Fundeb, o da Merenda escolar e o de Educação". Embora o CME seja muito valorizado no texto que antecede o PME propriamente, ele não possui um lugar de destaque, cabendo apenas a deliberação de normas para a Educação Infantil e para a modalidade de Educação de Jovens e Adultos (EJA).

Dentre os planos analisados, o CME de ltaboraí destaca-se, pois além de estar presente nas áreas já citadas, esse conselho também consta nas metas da Educação a Distância (EaD), devendo criar "[... instrumentos que possibilitem avaliação e acompanhamento dos programas EaD oriundos de políticas públicas e/ou de instituições privadas" (ITABORAí, 2008a, p. 68 e 91). Cabe também ao CME "[...] implementar as diretrizes para o ensino da História e 
Cultura Afro-Brasileira e dos Povos Indígenas no Brasil, [... . promovendo encontros e debates para servir como orientação para uma prática pedagógica numa perspectiva emancipadora e construtiva".

Embora a presença do CME na promoção da Educação Básica nos PMEs em tela ocorra de forma diversificada, visto que o CME não consta necessariamente nas mesmas metas/ações, cumpre salientar que diferentes funções que competem ao CME estão em alguma medida nos planos investigados. As funções normativa e deliberativa foram privilegiadas, por exemplo, no campo da Educação Infantil, como também no Ensino Fundamental. A fiscalizadora também está presente de forma significativa, especialmente no controle dos recursos financeiros. Embora do ponto de vista quantitativo a função mobilizadora tenha sido menos expressiva, importa ressaltar sua presença nas metas que incentivam a população a participar dos Conselhos, buscando ampliar o debate em torno da educação. Tal cenário sugere certo reconhecimento do lugar do CME na elaboração das políticas locais.

\section{CMEs no acompanhamento e avaliação dos PMEs}

A avaliação stricto sensu de planos de educação consiste em um importante componente do processo de planejamento (KIPNIS; ALGARTE, 200 1) e, a um só tempo, em mecanismo que viabiliza o acompanhamento, a análise e o julgamento da execução de todas as suas fases. Isso significa considerar a avaliação das políticas educacionais como um processo que implica interatividade e negociações, marcado por certa progressibilidade (BONAMINO; FRANCO; SOUSA; MAIA, 2006), expondo, portanto, dimensões políticas, pois, antes de tudo, resulta de uma construção social. Assim, a avaliação de planos de educação passa a ser entendida não apenas como instrumento articulado à correção dos seus rumos pelos governos, útil aos processos de regulação das políticas públicas (BARROSO, 2006), mas como forma política voltada à prestação de contas dos governos à sociedade, com vistas ao conhecimento de seu desempenho, resultados e efeitos (DRAIBE, 2001).

Todavia, a avaliação dessas políticas vem apresentando grandes desafios para a área educacional, a começar por sua complexidade teórica e, em especial, metodológica, passando pela diversidade dos processos participativos (DOURADO, 2010). Além disso, parece que no Brasil não há uma 
tradição de valorização dos resultados dos processos avaliativos que, por exemplo, retroalimentem o planejamento educacional (BONAMINO; FRANCO; SOUSA; MAIA, 2006), o que minora ainda mais a sua importância institucional e sociopolítica, configurando formal a previsão do acompanhamento e avaliação nos planos de educação.

No que tange ao PNE 2001-2010, observa-se que a lei que o regulamentou - Lei n 10.172 -, determinou que a "A União, em articulação com os estados, o Distrito Federal, os municípios e a sociedade civil" (BRASIL, 2001 ) deveria proceder à efetivação de avaliações periódicas relativas à implementação desse plano nacional, principiando-as no "quarto ano de vigência desta Lei" (BRASIL, 2001). Pressupôs, ainda, acompanhamento e avaliação sistemáticos, constituindo-se em subsídio estratégico e indispensável ao monitoramento e regulação do desenvolvimento das políticas públicas associadas a esse tipo de planejamento educacional, assim como em possibilidade de participação sociopolítica e transparência institucional. Em lei anterior ao próprio PNE 2001 2010 - Lei n 9.131, de 24 de novembro de 1995 (BRASIL, 1995) - o Conselho Nacional de Educação (CNE) é incumbido, justamente, de "subsidiar a elaboração e acompanhar a execução do Plano Nacional de Educação".

Assim como no PNE 2001-2010 (BRASIL, 2001), todos os PMEs em tela dedicam seção específica nos seus documentos ao acompanhamento e avaliação do plano - alguns a discutindo genericamente, enquanto que outros definindo metas/objetivos específicos a serem perseguidos. Parece haver certo consenso entre os PMEs da RM do Rio de Janeiro de que o seu acompanhamento e avaliação sistemáticos consistem em subsídio estratégico e indispensável ao monitoramento do desenvolvimento local das políticas públicas de educaçãob, pois, se considerado que se trata de um plano para dez anos, "[...] por si só já exige cautela e avaliação" (MARICÁ, 2008, p. 13) de modo a: i) "[...] garantir a efetiva execução dos objetivos e metas" (ITABORAÍ, 2008 , p. 125), ii) atribuir-the "[...] segurança no prosseguimento das ações ao longo do tempo" (SÃO GONÇALO, 2006b, p. 9), iii) promover "[...] adaptações e medidas corretivas [...]" de percurso (UAPERI, 2008a, p. 87), iv) balizar "[... tomada de decisões sempre que o redirecionamento das ações se fizer necessário" (RIO DE JANEIRO, 2008a, p. 78), v) realimentar a "dinâmica do próprio processo" (TANGUÁ, 2009a, p. 124), vi) estabelecer sintonia com as "[...] mudanças da realidade social, econômica e educacional do sistema 
[...]" (SEROPÉDICA, 201 1, p. 41 ) e por meio da "[... elaboração de constantes diagnósticos" (NILÓPOLIS, 2001, p. 21 ).

Assim, a maioria dos PMEs em tela prevê a realização de avaliações periódicas7, sendo que apenas Nilópolis e Queimados definem periodicidade similar à indicada pelo PNE 2001-2010, qual seja, a quadrianual. Já ltaboraí e Niterói determinam periodicidade trianual, enquanto os demais planos Japeri, Rio de Janeiro, São Gonçalo e Seropédica - optaram por avaliações bianuais, cuja temporalidade julga-se de maior produtividade para esse tipo de planejamento educacional, pois permitem, em um espaço de dez anos, maior número de intervenções, embora demandando, em tempos mais reduzidos, maior atenção sobre o acompanhamento da implantação do plano por parte do poder público e da sociedade civil local.

Do ponto de vista dos espaços institucionais destinados à realização das ações de acompanhamento e avaliação dos PMEs, quase todos os planos sob análise salientam o papel da Câmara Municipal de Vereadores ${ }^{8}$, reiterando sua competência na aprovação de medidas que, apoiadas nos resultados dessas avaliações, visem a ajustes das metas e objetivos previstos, assim como eventuais correções e distorções no seu desenvolvimento. No seu conjunto, reconhecem o papel deliberativo do Poder Legislativo local em torno dos ajustes demandados pela operacionalização dos PMEs, mas entendem que a responsabilidade pelo seu acompanhamento e avaliação concerne, de fato, aos Sistemas Municipais de Ensino.

Assim, alguns planos responsabilizam diretamente a SME pelas avaliações da implementação do PME, isto articuladamente ao CME e a "[...] todas as entidades sociais que tenham legítimo interesse no desenvolvimento de uma educação de qualidade no Município[...]" (NILÓPOLIS, 2001, p. 21), ou mesmo sinalizando que o "[...] melhor segmento de acompanhamento e avaliação do Plano é a própria sociedade, por meio da organização de seus atores, sejam eles governamentais ou não [...]" (TANGUÁ, 2009a, p. 124).

Outros planos deslocam essa centralidade da SME para o CME, embora reconheçam o papel indutor dessa Secretaria no desenvolvimento do PME. Itaboraí (2008) e São Gonçalo (2006b), por exemplo, entendem que as avaliações periódicas dos seus respectivos PMEs devam ter à frente os CMEs, isto com a colaboração de outros Conselhos locais, como do Fundeb, do Conselho de Alimentação Escolar, do Conselho Tutelar, do Conselho da Saúde 
e de Assistência Social, do Conselho da Criança e do Adolescente, entre outros. Os relatórios de acompanhamento produzidos pelo CME constituiriam, então, a base para a revisão dos objetivos e metas de cada eixo do PME de Itaboraí, perspectiva também adotada pelo Rio de Janeiro (2008a) e por Japeri (2008a, p. 87), estes também entendendo que cabe ao CME a coordenação geral dos seus planos. Niterói, no próprio corpo da lei do PME, em seu art. $2^{\circ}$, atribuiu ao CME a incumbência pelas ações de acompanhamento e avaliação, "[...] em estreito diálogo com a sociedade civil" (NITERÓI, 2008). Já Queimados (2009a), embora defina que os responsáveis diretos pela avaliação serão a Câmara Municipal e a SME, ressalta que é de competência do seu CME a criação de mecanismos de acompanhamento e dos instrumentos destinados à avaliação do plano.

Em paralelo, determinadas localidades buscam também instituir espaços e modos específicos ao acompanhamento e avaliação dos seus respectivos PMEs, como, por exemplo, a criação, pelo CME, de um Núcleo Municipal de Acompanhamento e Avaliação do PME (ITABORAí, 2008), de um Fórum Permanente de Acompanhamento e Avaliação do PME (SEROPÉDICA, 2011 ). Notam-se, ainda, previsões de constituição de um Sistema Municipal de 208 Avaliação coordenado pelo CME (RIO DE JANEIRO, 2008a; NITERÓI, 2008) ou pela SME (NILÓPOLIS, 200 la), todos, proclamadamente, a serem também compostos por representação de diversos segmentos do poder público e da sociedade civil?.

Cabe destacar que somente Niterói (2008; 2010a) aponta mecanismos voltados à publicização local do PME, especialmente quando prevê a sua publicação "[...] em forma de livreto, com distribuição gratuita nos diversos setores da sociedade" (NITERÓl, 2010a, p. 20). Não obstante, Nilópolis (200 1 a), Queimados (2009) e Rio de Janeiro (2008a; 2008b), de forma genérica, ressaltam que o poder público local deverá empenhar-se na divulgação dos seus respectivos PMEs e dos resultados das avaliações, contudo, sem indicar os instrumentos a serem empregados, tampouco as instituições do Sistema Municipal de Ensino a serem responsabilizadas por esta tarefa, não ficando claro se constituiria em prerrogativa do CME.

Assim, para alguns PMEs, o acompanhamento e avaliação periódicos do plano configuram responsabilidade direta da SME, enquanto, para outros, do CME. Em alguns poucos casos, há também destaque para a importância da participação sociopolítica nesse processo. No entanto, do mesmo 
modo que ocorre com a elaboração desses planos, a centralidade do seu acompanhamento e avaliação, embora contextualizada na esfera do Sistema Municipal de Ensino, não se encontra necessariamente posta nesses Conselhos, podendo constituir-se em atribuição principal do órgão executivo local e não do colegiado.

\section{Considerações finais}

Conforme visto, a maior parcela dos PMEs aqui examinados veio a ser aprovada em anos avizinhados ao término da vigência do PNE 2001 2010 , justamente quando principiavam as discussões sobre o novo PNE, o que significa que, mesmo antes da sua efetiva implantação, já exprimiam grandes defasagens e desalinhamentos em relação às metas e objetivos daquele primeiro plano nacional. Tal fato, decerto, veio a contribuir significativamente para uma desvinculação entre as diretrizes e decisões desses planos locais e o PNE 2001-2010. Nesta perspectiva, é importante destacar que, segundo levantamento sobre as avaliações desse plano realizado pelo CNE (BRASIL, 2009), um dos aspectos que mais contribuiu para o insucesso desse plano nacional consistiu, justamente, na desarticulação em relação aos planos municipais e estaduais. De acordo com o esperado, esses planos deveriam indicar coesão, de modo a refletir a identidade e as competências educacionais de cada esfera federada, e, a um só tempo, integração em relação ao PNE, garantindo, com isto, a sua efetividade.

A par da recorrente falta de informações e imprecisões nos planos examinados, foi possível estabelecer algumas inferências acerca do lugar ocupado pelos CMEs nesses planos, no sentido do papel desempenhado na construção dos PMEs, do previsto para a sua atuação na promoção das etapas e modalidades da Educação Básica de competência municipal e, ainda, do acompanhamento e avaliação do plano propriamente dito.

Ainda que os dez municípios analisados tenham destacado a participação da sociedade civil na construção dos respectivos planos e possuam CMEs instituídos, a referência feita aos Conselhos no processo de elaboração dos PMEs foi tímida. Considerando que o CME é um órgão integrante do Sistema Municipal de Ensino, e que possui composição plural lgoverno e sociedade civil) - o que supostamente tenderia a facilitar uma construção coletiva 
e democrática na gestão educacional -, haveria de se esperar uma presença mais contundente desses Conselhos nos planos em questão.

As análises também evidenciam que a previsão de atuação do CME na promoção das etapas e modalidades da Educação Básica desses PMEs ocorre de forma diferenciada, pois o CME consta em metas e ações de cunho bastante diverso, não se mostrando, quer uniforme ao longo desses eixos temáticos de um mesmo plano, quer sistemática entre os seus componentes (diretrizes, objetivos e metas). Ainda assim, observa-se que as funções arroladas tendem a dar relativa visibilidade acerca da importância técnica e política dos CMEs.

Da mesma forma que ocorre com a construção desses PMEs, a centralidade do seu acompanhamento e avaliação, embora contextualizada na esfera do Sistema Municipal de Ensino, não se encontra necessariamente posta nesses Conselhos. Observa-se que há uma forte tendência em configurar essas ações como de responsabilidade direta da SME, em que pese o fato de alguns PMEs entenderem que consistem em prerrogativa do CME, mas muito raramente sinalizando para a importância da participação sociopolítica neste processo.

210 documental, circunscritamente aos PMEs aqui analisados, não foi atribuído aos CMEs papel de relevo ao longo do processo de discussão e elaboração dos planos locais, reservando-lhes uma atuação mais pontual em termos da promoção das etapas e modalidades da Educação Básica de competência municipal e, ao mesmo tempo, tímida no que tange ao acompanhamento e avaliação do plano. Assim, esses órgãos vêm ocupando pouca importância estratégica para a gestão democrática da educação local, o que significa que o seu processo de institucionalização nos Sistemas Municipais de Ensino ainda apresenta restrições quanto ao exercício das competências e funções que the são características, especialmente no campo do planejamento educacional, enquanto o seu valor sociopolítico ainda carece de efetivo reconhecimento.

A análise dos PMEs da RM do Rio de Janeiro, até aqui levada a efeito, revela também uma nítida tendência à baixa cooperação intermunicipal, pois se constatou a ausência de um enfoque regional-metropolitano no conjunto de decisões desses planos, o que caracteriza certo isolamento entre os planejamentos locais da educação, e entre estes e um possível planejamento integrado para a área. 


\section{Notas}

1 Relaciona-se ao projeto de pesquisa "Os Planos Municipais de Educação (Brasil) e as Cartas Educativas Municipais (Portugal): perspectiva comparada entre as Regiões/Áreas Metropolitanas do Rio de Janeiro e do Porto", sob coordenação, no Brasil, do Prof. Dr. Donaldo Bello de Souza, da UERJ e, em Portugal, da Profa. Dra. Dora Castro, do Instituto Politécnico do Porto ISOUZA; CASTRO, 20111 .

2 estado do Rio de Janeiro veio a ter o seu PEE aprovado somente no nono ano de vigência do PNE 2001-2010 (BRASIL, 2001), ou seja, às vésperas do seu término, quando, pela Lei ${ }^{\circ}$ 5.597, de 18 de dezembro de 2009 (RIO DE JANEIRO, 2009; 2009a), atendeu ao que fora previsto no art. 10, inciso III da Ldben n 9.394, de 20 de dezembro de 1996 (BRASIL, 1996; VALE; MENEZES; VASCONCELOS, 20121.

3 Em 2011 e 2012, os autores e colaboradores adotaram três ações: i) consulta via internet aos sítios relativos aos municípios - Prefeitura Municipal, SME, CME e Câmara Municipal -, assim como a diversas bases de dados disponíveis nesta rede, ii) consulta, in loco, ao setor de arquivo relativo à Comissão de Educação da Aleri; iii) contato telefônico junto às SMEs e aos CMEs dessas localidades.

4 Além dos 10 PMEs da RM do Rio de Janeiro, registraram-se outros 23 planos: Cabo Frio, Rio Bonito, Angra dos Reis, Mangaratiba, Campos dos Goytacazes, Conceição de Macabu, Macaé, São Fidélis, São João da Barra, Italva, Itaperuna, Santo Antonio de Pádua, Nova Friburgo, Petrópolis, Areal, Mendes, Miguel Pereira, Paraíba do Sul, Vassouras, Barra do Piraí, Resende, Rio Claro e Rio das Flores.

5 A RM do Rio de Janeiro foi estabelecida pela LC n²0, de 01 de julho de 1974 (BRASIL, 1974), que, no Capítulo II, determinava a fusão dos estados do Rio de Janeiro e da Guanabara. A seção IV ("Da Região Metropolitana do RJ"), no art. 19, estabeleceu 14 municípios como componentes iniciais. $\bigcirc$ art. 21 determinava a criação de um fundo contábil para financiar programas e projetosprioritários dessa RM.

6 Não se identificaram nos documentos relativos aos PMEs de Niterói $(2008,2010)$ e Queimados (2009, 2009a) elementos explícitos sobre concepções ou princípios concernentes à questão do acompanhamento e avaliação desses planos.

7 Não se identificaram nos documentos relativos aos PMEs Maricá (2008, 20 10) e Tanguá (2009, 2009a) informações a respeito da periodicidade prevista para a realização das avaliações.

8 Não se identificaram nos documentos relativos aos PMEs de Maricá (2008, 2010) e Tanguá (2009, 2009a) informações a respeito do papel da Câmara Municipal de Vereadores no processo de acompanhamento e avaliação do plano.

9 Não se identificou nos documentos relativos ao PME de Maricá $(2008,2011$ ) previsão de órgãos/atores sociais a serem envolvidos no processo de acompanhamento e avaliação do plano. 


\section{Referências}

BARBOZA, Edir Neves. A constituinte escolar em Dourados (2000-2004): um movimento em buscada democratização da Escola Pública. 2008. 208f. Dissertação (Mestrado em Educação) - Programa de Pós-Graduação em Educação, Fundação Universidade Federal do Mato Grosso do Sul, Campo Grande, 2008.

BARDIN, Laurence. Análise de conteúdo. 3. ed. Lisboa: Edições 70, 2004.

BARROSO, João. Introdução: a investigação sobre a regulação das políticas públicas de educação em Portugal. In: BARROSO, João (Org.). O Estado e a educação: a regulação transnacional, a regulação nacional e a regulação local. Lisboa: Educa, 2006.

BONAMINO, Alicia; FRANCO, Creso; SOUSA, Sandra Zákia; MAIA, Maurício. Avaliação de políticas educacionais. In: BRASIL. Ministério da Educação. Secretaria de Educação Básica. Pradime: Programa de Apoio aos Dirigentes Municipais de Educa. Brasília: MEC/ SEB, 2006. (Caderno de Textos, 1).

BORDENAVE, Juan Diaz. O que é participação. 6. ed. São Paulo: Brasiliense, 2011.

BRASIL. Lei Complementar n²0, de 1 de julho de 1974. Dispõe sobre a criação de Estados

212 e Territórios. Diário Oficial [da] União da República Federativa do Brasil, Brasília, DF, 1 jul. de 1974.

Constituição [de 1988] da República Federativa do Brasil. Diário Oficial [da] União da República Federativa do Brasil, Brasília, DF, 5 out. 1988.

Lei n 9.131, de 24 de novembro de 1995. Altera dispositivos da Lei n. 4.024, de 20 de dezembro de 1961, e dá outras providências. Diário Oficial [da] União da República Federativa do Brasil, Brasília, DF, 25 nov. 1995.

Lei n 9.394, de 20 de dezembro de 1996. Estabelece as Diretrizes e Bases da Educação Nacional. Diário Oficial [da] União da República Federativa do Brasil, Brasília, DF, 23 dez. 1996.

Lei n 10.172, de 09 de janeiro de 2001. Aprova o Plano Nacional de Educação (PNE). Diário Oficial [da] União da República Federativa do Brasil, Brasília, DF, 10 jan. 2001.

Ministério da Educação. Secretaria de Educação Básica. Coordenação Geral de Articulação e Fortalecimento Institucional dos Sistemas de Ensino. Programa Nacional de 
Capacitação de Conselheiros Municipais de Educação Pró-Conselho: guia de consulta. Brasília, DF: MEC/SEB, 2007.

Conselho Nacional de Educação. Portaria CNE/CP n 10, de 6 de agosto de 2009. Indicações para subsidiar a construção do Plano Nacional de Educação 2011 2020. Brasília: CNE/CP, 2009.

Projeto de Lei do Plano Nacional de Educação (PNE 201 1-2020): Projeto em tramitação no Congresso Nacional - PL n 8.035/2010. Brasília, DF: Câmara dos Deputados, Edições Câmara, 2011.

Instituto Brasileiro de Geografia e Estatística. Diretoria de Pesquisas. Coordenação de População e Indicadores Sociais. Perfil dos municípios brasileiros 2011. Rio de Janeiro: IBGE, 2012.

Lei n 13.005, de 25 de junho de 2014. Aprova o Plano Nacional de Educação PNE e dá outras providências. Diário Oficial [da] União da República Federativa do Brasil, Brasília, DF, 26 jun. 2014.

CALDERÓN, Adolfo Ignacio. Conselhos municipais: representação, cooptação e modernização da política patrimonialista. In: SOUZA, Donaldo Bello de (Org.). Conselhos municipais e controle social da educação: descentralização, participação e cidadania. São Paulo, Xamã, 2008.

CALDERÓN, Adolfo Ignácio; MARIM, Vlademir. Educação e políticas públicas: os conselhos municipais em questão. Teias - Revista da Faculdade de Educação da UERJ, Rio de Janeiro, v. 3, n. 6, p. 39-47, jul./dez. 2002.

CARVAlHO, Jose Murilo. Cidadania no Brasil: o longo caminho. 3. ed. Rio de Janeiro: Civilização Brasileira, 2002.

DOURADO, Luiz Fernandes. Avaliação do Plano Nacional de Educação 200 1-2009: questões estruturais e conjunturais de uma política. Educação \& Sociedade, Campinas, v. 31 , n. 112 , p. 677-705, jul./set. 2010.

DRAIBE, Sônia Miriam. Avaliação de implementação: esboço de uma metodologia de trabatho em políticas públicas. In: BARREIRA, Maria Cecília Roxo Nobre; CARVALHO, Maria do Carmo Brant de (Org.). Tendências e perspectivas na avaliação de políticas e programas sociais. São Paulo: IEE/PUC-SP, 2001.

DUARTE, Marisa Ribeiro Teixeira; SANTOS, Maria Rosimary Soares. Educação e desenvolvimento: planejamento de ações governamentais e novos modos de regulação social? In: 
SOUZA, Donaldo Bello de; MARTINS, Ângela Maria (Org.). Planos de educação no Brasil: planejamentos, políticas, práticas. São Paulo: Loyola, 2014.

GOHN, Maria da Glória. Conselhos gestores e participação sociopolítica. São Paulo: Cortez, 2001.

GOHN, Maria da Glória. Conselhos municipais de acompanhamento e controle social em Educação: participação, cidadania e descentralização? In: SOUZA, Donaldo Bello de (Org.). Conselhos municipais e controle social da educação: descentralização, participação e cidadania. São Paulo, Xamã, 2008. p. 97-1 13.

ITABORAí (Município). Lei n² 2.077, de 28 de novembro de 2008. Institui o Plano Municipal de Educação de Itaboraí. Jornal Itaboraí, Itaboraí, n. 138, 29 nov. 2008.

Plano Municipal de Educação de Itaboraí: Anexo da Lei n².077, de 28 de novembro de 2008. Jornal Itaboraí, Itaboraí, n. 138, 29 nov., 2008a.

JAPERI (Município). Lei $\mathbf{n}^{\circ}$ 1.155, de 10 de abril de 2008. Aprova o Plano Municipal de educação e dá outras providências. Prefeitura Municipal de Japeri, Secretaria Municipal de Governo. Japeri, 10 abr. 2008. Disponível em: <http://www.japeri.ri.gov.br/PublicFiles/ leis/lei2008.pdf>. Acesso em: 28 dez. 2012.

214 Plano Municipal de Educação: Município de Japeri. Japeri: Secretaria Municipal de Educação e Cultura; Conselho Municipal de Educação, 2008a. Disponível em: <http:// www.japeri.ri.gov.br/PublicFiles/leis/lei2008.pdf>. Acesso em: 28 dez. 2012.

KETELE, Jean-Marie de; ROEGIERS; Xavier. Metodologia da recolha de dados: fundamentos dos métodos de observações, de questionários, de entrevistas e de estudo de documentos. Lisboa: Instituto Piaget, 1993.

KIPNIS, Bernardo; ALGARTE, Roberto. Planejamento e avaliação educacionais. In: WITTMANN, Lauro Carlos; GRACINDO, Regina Vinhaes (Org.). O estado da arte em política e gestão da educação no Brasil 1991-1997. Campinas: Autores Associados; São Paulo: Anpae, 2001.

LUCHMANN, Lígia Helena Hahn. A representação no interior das experiências de participação. Lua Nova: Revista de Cultura e Política, São Paulo, n. 70, p. 139-170, 2007.

MARICÁ (Município). Lei n².281, de 19 de dezembro de 2008. Aprova o Plano Municipal de Educação. Jornal Oficial de Maricá, Maricá, v. 2, n. 129, 29 dez. 2008.

MONLEVADE, João Antonio. A importância do Conselho Municipal de Educação na elaboração, implantação e acompanhamento da execução do Plano Municipal de Educação. In: 
BRASIL. Ministério da Educação. Secretaria de Educação Básica. Programa Nacional de Capacitação de Conselheiros Municipais de Educação Pró-Conselho: caderno de referência. Brasilia, DF: MEC/SEB, 2004.

NILÓPOlIS (Município). Anexo a Lei n 5.982, de 29 de novembro de 2001: Plano Municipal de Educação. Secretaria Municipal de Educação, Jornal A Voz dos Municípios Fluminenses, Nilópolis, 28 dez. 2001.

Lei n 5.982, de 13 de dezembro de 2001. Aprova o Plano Municipal de Educação com previsão de vigência de 2002 a 201 1, e dá outras providências. Jornal A Voz dos Municípios Fluminenses, Nilópolis, 28 dez. 2001 a.

NITERÓl (Município). Lei n².610, de 31 de outubro de 2008. Aprova o Plano Municipal de Educação de Niterói e dá outras providências. A Tribuna, Niterói, 01 nov. 2008.

Lei n ${ }^{\circ} 2.707$, de 25 de março de 2010. Aprova a Complementação do Plano Municipal de Educação de Niterói e dá outras providências. Jornal O Fluminense, Niterói, 25 mar. 2010.

NOGUEIRA, Marco Aurélio. A dimensão política da descentralização participativa. São Paulo em Perspectiva, São Paulo, v. 11, n. 3, p. 8-19, jun./set. 1997.

OLIVEIRA, Maria José Houly Almeida de; ARAGÃO, Maria Helena de Melo. Plano Municipal de Educação - PME: a experiência do município de Arapiraca. In: COLÓQUIO INTERNACIONAL EDUCAÇÃO E CONTEMPORANEIDADE, 4; 2010. Laranjeiras. Anais... Laranjeiras: Universidade Federal de Sergipe. 11 p.

POMPEU, Gina Vidal Marcílio. Gênese e redefinição do controle social da educação no Brasil. In: SOUZA, Donaldo Bello de (Org.). Conselhos municipais e controle social da educação: descentralização, participação e cidadania. São Paulo, Xamã, 2008.

QUEIMADOS (Município). Lei $\mathbf{n}^{\circ}$ 972, de 24 de dezembro de 2009. Aprova $\circ$ Plano Municipal de Educação de Queimados e dá outras providências. Queimados, Gabinete do Prefeito, 24 dez. 2009 (digitado).

Plano Municipal de Educação: Queimados 2009-2019. Queimados: Secretaria Municipal de Educação, 2009a.

RIO DE JANEIRO (Estado). Fundação Centro Estadual de Estatísticas, Pesquisas e Formação de Servidores Públicos do Rio de Janeiro. Anuário estatístico do Estado do Rio de Janeiro 2010. Rio de Janeiro: CEPERJ, 2010 1. CD-ROM. 
Lei n 5.332, de 24 de novembro de 2008. Dispõe sobre as transferências de receita aos municípios que constituírem o Plano Municipal de Educação. Diário Oficial [do] Estado do Rio de Janeiro, Rio de Janeiro,25 nov. 2008.

Lei no 5.597, de 18 de dezembro de 2009. Institui o Plano Estadual de Educação - PEE-RJ, e dá outras providências. Diário Oficial [do] Estado do Rio de Janeiro, Rio de Janeiro, 19 dez. 2009.

Plano Estadual de Educação do Rio de Janeiro. Rio de Janeiro, Secretaria de Educação, 2009a.

RIO DE JANEIRO (Município). Lei n 4.866, de 02 de julho de 2008. Aprova o Plano Municipal de Educação e dá outras providências. Diário Oficial [do] Estado do Rio de Janeiro, Rio de Janeiro, 04 jul. 2008a.

Plano Municipal de Educação da cidade do Rio de Janeiro. Rio de Janeiro: Secretaria Municipal de Educação, 2008b. Disponível em: <http://mail.camara.ri.gov.br/ APL/Legislativos/contlei.nst/69d90307244602bb032567e800668618/cd432a5690 c5b5da032576ac00727775? OpenDocument>. Acesso em: 19 jul. 2012.

RODRIGUES, Lea Carvalho. Análises de conteúdo e trajetórias institucionais na avaliação 216 de políticas públicas sociais: perspectivas, limites e desafios. CAOS - Revista Eletrônica de Ciências Sociais, João Pessoa, n. 16, p. 55-73, mar. 2011.

SANTOS, Ana Lúcia Ribeiro dos. Plano e gestão da educação municipal: relação entre proposta e efetivação. Curitiba, 2004. 225f. Dissertação (Mestrado em Educação) - Programa de Pós-Graduação em Educação, Universidade Federal do Paraná, Curitiba, 2004.

SÃO GONÇALO (Município). Lei nº 056, de 01 de agosto de 2006. Aprova o Plano Municipal de Educação e dá outras providências. Atos Oficiais da Prefeitura Municipal de São Gonçalo, São Gonçalo, 24 ago. 2006.

Parecer CME n 005, de 21 de outubro de 2004. Delibera sobre o Plano Municipal de Educação de São Gonçalo. Atos Oficiais da Prefeitura Municipal de São Gonçalo, São Gonçalo, 24 ago. 2006a.

Plano Municipal de Educação de São Gonçalo - 2004. Atos Oficiais da Prefeitura Municipal de São Gonçalo, São Gonçalo, 24 ago. 2006 b.

SEROPÉDICA (Município). Lei n ${ }^{\circ}$ 426, de 2 de janeiro de 2012. Institui o Plano Municipal de Seropédica. Câmara Municipal de Seropédica, Seropédica, 2 jan. 2012. 
PME - Plano Municipal de Seropédica. Seropédica: Prefeitura Municipal de Seropédica, Secretaria Municipal de Educação, 2011.

SOUZA, Donaldo Bello de. Apresentação. In: SOUZA, Donaldo Bello de (Org.) Conselhos municipais e controle social da educação: descentralização, participação e cidadania. São Paulo: Xamã, 2008.

SOUZA, Donaldo Bello de; CASTRO, Dora Fonseca. Projeto de investigação "Os Planos Municipais de Educação (Brasil) e as Cartas Educativas Municipais (Portugal): perspectiva comparada entre as Regiões/Áreas Metropolitanas do Rio de Janeiro e do Porto. Rio de Janeiro: Nephem/FE/Uerj; Porto: InEd/ESE/IPPorto, 2011 . (Versão 1.6).

SOUZA, Donaldo Bello de; DUARTE, Marisa Ribeiro Teixeira. Planos de educação no Brasil: projeções do sistema nacional de educação e suas variantes subnacionais. In: SOUZA, Donaldo Bello de; MARTINS, Ângela Maria (Org.). Planos de educação no Brasil: planejamentos, políticas, práticas. São Paulo: Loyola, 2014.

SOUZA, Donaldo Bello de; MENEZES, Janaína Specht da Silva. Estudo crítico-exploratório sobre os planos estaduais de educação (PEEs) no Brasil: contribuições para formulações e reformulações decorrentes do novo Plano Nacional de Educação (PNE). Rio de Janeiro: Nephem/Uerj; Neephi/Unirio, jun. 2014. 98p. (Relatório de pesquisa).

SOUZA, Donaldo Bello de; SOUSA, Gustavo José Albino de. Planos nacionais, estaduais e municipais de educação no Brasil: balanço quali-quantitativo sobre a literatura acadêmica (1996-2010). Agenda Social, Campos dos Goytacases,v. 6, p. 50-70, 2012.

SOUZA, Donaldo Bello de; VASCONCELOS, Maria Celi Chaves. CMEs no estado do Rio de Janeiro: considerações sobre o funcionamento institucional e sociopolítico a partir de 28 de suas localidades. In: VALLE, Bertha de Borja Reis do; VASCONCELOS, Maria Celi Chaves (Org.). Conselhos municipais de educação: organização e atribuições nos sistemas de ensino do estado do Rio de Janeiro. Rio de Janeiro: Quartet; Faperj, 2012.

.CMEs: espaços de controle social? In: SOUZA, Donaldo Bello de (Org.). Conselhos municipais e controle social da educação: descentralização, participação e cidadania. São Paulo, Xamã, 2008.

CMEs no estado do Rio de Janeiro: sobre a autonomia concedida e a submissão herdada. In: SOUZA, Donaldo Bello de, DUARTE, Marisa Ribeiro Teixeira, OLIVEIRA, Rosimar de Fátima. CMEs no Brasil: uma cartografia a partir de estudos teórico-empíricos. In. SOUZA, Donaldo Bello de (Org.). Mapa dos conselhos municipais de educação no Brasil. São Paulo: Loyola, 2013. 
SOUZA, Márcio Jocerlan de. Processo de elaboração do plano municipal de educação do Assú/RN e a participação dos professores. 2006. Natal, 142f. Dissertação (Mestrado em Educação) - Programa de Pós-Graduação em Educação, Universidade Federal do Rio Grande do Norte, Natal, 2006.

TANGUÁ (Município). Lei $\mathbf{n}^{\circ}$ 0717, de 24 de novembro de 2009. Institui o Plano Municipal de Educação. Prefeitura Municipal de Tanguá, Gabinete do Prefeito, Tanguá, 24 nov. 2009.

Plano Municipal de Educação: Tanguá - RJ. Prefeitura Municipal de Tanguá, Secretaria de Educação, Esporte e Lazer, 2009a (digitado).

VALLE, Bertha de Borja Reis do; MENEZES, Janaina Specht da Silva; VASCONCELOS, Maria Celi Chaves. Plano Estadual de Educação do Rio de Janeiro: a trajetória de uma legislação. Rio de Janeiro: Quartet, 2012.

VASCONCELOS, Maria Celi Chaves; PEIXOTO, Leonardo Ferreira; VIDAL, Patrícia de Fátima Evaristo. Conselhos municipais no estado do Rio de Janeiro: uma análise comparativa a partir do Sicme. In: VAlLE, Bertha de Borja Reis do; VASCONCELOS, Maria Celi Chaves (Org.). Conselhos municipais de educação: organização e atribuições nos sistemas de ensino do estado do Rio de Janeiro. Rio de Janeiro: Quartet; Faperj, 2012.

218 VILLELA, Viviane Merlim Moraes. O conceito de cidadania na definição de políticas públicas educacionais: debates e impasses no processo de elaboração do Plano Municipal de Educação de Niterói/RJ. Niterói, 2008. 245f. Dissertação (Mestrado em Educação) - Programa de Pós-Graduação em Educação, Universidade Federal Fluminense, Niterói, 2008.

WERLE, Flávia Obino Corrêa; BARCELLOS, Jorge Alberto Soares. Plano Municipal de Educação e a afirmação de princípios para a educação local. Ensaio: Avaliação em Políiticas Públicas em Educação, Rio de Janeiro, v. 16, n. 61, p. 51 5-542, out./dez. 2008.

ZARAGOZA, José Manuel Esteve. O malestar docente: a sala de aula e a saúde dos professores. Bauru: EDUSC, 1999.

Prof. Dr. Donaldo Bello de Souza Universidade do Estado do Rio de Janeiro Faculdade de Educação Departamento de Política, Gestão e Avaliação da Educação 
Líder do Grupo de Pesquisa em Política e História da Educação Municipal| CNPq/ MCT

E-mail | donaldobello@gmail.com

Profa. Dra. Alzira Batalha Alcântara Universidade do Estado do Rio de Janeiro Faculdade de Educação da Baixada Fluminense Universidade Estácio de Sá Programa de Pós-Graduação em Educação Grupo de Pesquisa em Política e História da Educação Municipal | CNPq/MCT E-mail | alzirabatalha@hotmail.com Recebido $1^{\circ}$ set. 2015 Aceito 6 jun. 2016 